\title{
A construção da imagem de Oswaldo Cruz
}

\author{
The construction of \\ Oswaldo Cruz's image
}

$\mathrm{O}$ swaldo Cruz é uma dessas figuras que se confundem com a história do Brasil. A biografia do médico-sanitarista brasileiro transcende, assim, a vida individual e se transforma em fato da biografia da nação. Os traços pessoais traduzem os traços da sociedade nacional. É preciso, no entanto, salientar que essa relação não é um dado, mas construção condicionada pela operação historiográfica que permite afirmar a relação entre história de vida e história nacional, instauradora de mitologias acerca do social.

Em estudo conhecido, Nara Britto (1995) buscou discutir a imagem pública de Oswaldo Cruz e seu lugar no imaginário coletivo, cumprindo a função de lançar bases para a relação medicina-sociedade no Brasil. Assim, a figura idealizada de Oswaldo Cruz serviu como instrumento de superação de conflitos e funcionou como elemento de solidariedade entre os médicos, aglutinando o movimento sanitarista. Em poucas palavras, a vida de Oswaldo Cruz, após sua morte em 1917, tornou-se um emblema para legitimar ações sociais que emergiam do seio do discurso médico-sanitarista e do campo científico.

Como mostra o relato de Verônica Martins de Brito, que compõe esta seção, o culto à memória de Oswaldo Cruz, ao longo dos vinte anos que se seguiram à sua morte, deu origem a movimentos correlatos envolvendo o combate ao câncer e a construção de uma imagem escultórica urbana. O que os identificava era o potencial de mobilização social e de arrecadação de recursos. O emblema Oswaldo Cruz serviria, então, como instrumento de aliança entre o campo da medicina e a sociedade.

Embora esses dois movimentos não tenham conseguido levar a cabo suas propostas, a intenção subjacente a eles não se perdeu. Hoje, no Rio de Janeiro, existe o Instituto Nacional do Câncer (Inca). Da mesma forma, nas ruas dessa cidade fixou-se uma estátua em homenagem a Oswaldo Cruz. Promovida pelo Conselho Federal de Cultura, foi inaugurada em 1972, ano do centenário de seu nascimento, no final da avenida Oswaldo Cruz, no bairro de Botafogo. Em posição contígua está situada a estátua de Carlos Chagas, inaugurada por iniciativa idêntica, poucos anos depois. Note-se que a construção do Inca não se deveu à memória de Oswaldo Cruz, e que a estátua erguida nem de longe se equipara às intenções da antiga Comissão Executiva do Monumento à Memória de Oswaldo Cruz.

Especificamente, a documentação existente registra que, desde 1917, a iniciativa em torno da imagem escultórica urbana de Oswaldo Cruz já havia se organizado para 
além da Capital Federal. Na Bahia, a iniciativa era liderada pelo regional Diário de Notícias. No Espírito Santo, por uma empresa de comércio de importação/exportação. Em São Paulo, a comissão regional registrou sua intenção no âmbito da rede de ensino. Em carta pública aos diretores escolares, definia-se o monumento como "valiosíssimo concurso moral, porquanto exprimirá, com singela eloqüência, a primeira adesão da posteridade encarnada nas almas juvenis daqueles que amanhã irão participar dos destinos da pátria e que ora estão sendo educados por vós no culto dos homens que souberam honrar o Brasil". ${ }^{1}$ Essas palavras de época ilustram bem o sentido que o monumento assumia. De um modo geral, era caracterizado como gesto em prol da formação do cidadão, fiel à linearidade dos tempos, ratificando a noção de história não como ação social, mas como lugar de realização do destino, que ganhava, com aquele monumento, uma aura sagrada. Nesse sentido, honrar o Brasil significava cultuar o passado histórico que engendrara o presente tal e qual. O passado tornavase fator de legitimidade da ordem social vigente, e a imagem escultórica de caráter histórico se impunha como recurso didático. ${ }^{2}$

O monumento a ser erguido era encarado não apenas como homenagem, mas como resgate de uma 'dívida' da nação e, principalmente, da capital da República, "a cidade mais diretamente beneficiada com as atividades do inolvidável sanitarista". ${ }^{3}$ A recordação de seus feitos memoráveis exprimia o agradecimento da sociedade pela construção de seu destino identificado com a ação heróica que a colocara "à altura da civilização". ${ }^{4} \mathrm{O}$ caráter biográfico do exemplo garantia bases afetivas para a identificação individual com ele. O sentimento de gratidão, compartilhado nessas bases a um só tempo afetivas e sagradas, terminava por definir a imagem da urbes como lugar de memória (Nora, 1984). Nesses termos, o símbolo afirma sua universalidade e generalização, instaurando simbolicamente a unidade nacional e investindo numa ordem harmonizada da sociedade.

A imaginária urbana do Rio de Janeiro constitui um acervo expressivo e importante. Está em sintonia com a antiga tradição social de inscrever a presença humana no espaço, desde os menires e dólmens pré-históricos, passando pela esfinge egípcia, pelas imagens mitológicas clássicas e pelas estátuas eqüestres dos monarcas do Antigo Regime. Essa tradição foi renovada à época da Revolução Francesa, que, ao promover uma nova ordem política, instaurou novas formas simbólicas e valorizou a arte pública, convertendo-as em elementos de mobilização e identidade social. A imaginária urbana contemporânea tem, então, seus limites definidos pela cultura e arte laicas, pela cidade burguesa e pelos princípios do liberalismo (Agulhon, 1988, 1979). A produção de imagens urbanas estreou no Brasil em 1864, com a inauguração da estátua eqüestre de d. Pedro I, trazendo a seguinte inscrição no pedestal: "A d. Pedro, a gratidão dos

\footnotetext{
${ }^{1}$ Casa de Oswaldo Cruz - Centro de Documentação: Fundo - Fundação Oswaldo Cruz, Seção Serviço Administrativo, Série Administração Geral, Subsérie Monumento à Memória de Oswaldo Cruz, Caixa 1 - Dossiê Correspondência - maço 1. Carta de 1917, assinada pelos membros da comissão paulista: dr. Celestino Bourroil, dr. Domingues Lopes, dr. Vieira Marcondes, dr. José Augusto Arantes, dr. João Florêncio Salles Gomes.

${ }^{2}$ Essa característica didática era recorrente na definição do papel social das imagens urbanas. Ver, por exemplo, La Tardé (1946).

${ }^{3}$ Idem Caixa 1 - Dossiê Correspondência - maço 8. Carta de 6 de outubro de 1952, do ministro de Educação e Saúde, Simões Filho, ao prefeito João Carlos Vital.

${ }^{4}$ Ibidem.
} 
brasileiros". A gratidão como enunciado tornou-se recorrente e predominante no universo das imagens urbanas, traduzindo a reunião harmônica entre Estado e sociedade, promovendo a lembrança do primeiro monarca, líder do projeto de independência e outorgante da primeira Constituição nacional.

Depois de recusar, em 1929, um projeto de Correa Lima, escultor de diversas obras distribuídas na cidade do Rio de Janeiro, o movimento pela memória de Oswaldo Cruz, acompanhando as tendências da promoção de imagens urbanas, organizou um primeiro concurso de projetos em 1938, que incluiu participantes estrangeiros e o conhecido artista brasileiro Bruno Giorgi. Esse concurso foi anulado, e se organizou um segundo, que elegeu, em 1939, projeto do escultor ítalo-paulista Julio Starace. A deflagração da Segunda Guerra Mundial e outras dificuldades impossibilitaram a conclusão do projeto. O lugar designado para abrigar a construção foi um terreno em frente ao Corte de Cantagalo, recém-aberto para facilitar a passagem entre a Lagoa Rodrigo de Freitas e o bairro de Copacabana, nas proximidades de onde hoje se localiza a estátua eqüestre de San Martín, um dos heróis dos movimentos de independência nacional latino-americanos. O terreno garantiria expressão ao monumento projetado. Tratava-se já de área nobre na cidade, ponto de circulação importante, com entorno natural privilegiado, composto por belo espelho d'água e pelo encontro de morros arborizados. Sendo produto de uma obra de engenharia viária, que recortara a pedra das montanhas circundantes, a área moldada pela intervenção humana deveria contribuir para realçar aquela nova paisagem e para valorizar a referência ao gênio da ciência. Segundo parecer, a comissão de julgamento de projetos avaliou-os com base nos seguintes aspectos: valor simbólico, valor técnico, valor estético, valor urbanístico e valor paisagístico. Esses critérios serviram para garantir "a expressão, na plástica, da obra de Oswaldo Cruz, sua evidência sintética, como realidade educativa e de prestígio à sua rememória; a seguir, a composição e a evidência de execução pelos detalhes exibidos; logo depois, a união destas duas qualidades, como entidade de beleza, no sentido geral; ainda sua situação em relação à área concedida, e, finalmente, sua ação espacial, na atmosfera do local". ${ }^{5}$ Ratificava-se, portanto, a intenção de fazer do monumento um recurso didático do civismo, ao mesmo tempo que se buscavam as soluções artística e paisagística.

Interessa, ainda, apontar o fato de que, entre os projetos apresentados, as referências escultóricas variavam entre alegorias da morte e da ciência. A imagem de Oswaldo Cruz ganhava conteúdo ao ser identificada com a vitória sobre a morte e com a agonia da doença, constituindo a ciência o instrumento dessa vitória, e a cura, sua realização. A biografia do cientista tornava-se resumo da história do espírito científico no Brasil, associando progresso com cura, a possibilidade de vida com o desenvolvimento do conhecimento e da razão. O que se contrapõe à morte é o saber, uma vez que é a ciência que garante a vida, viabilizando a cura da doença. As qualidades afetivas e sagradas identificadas com o sentimento da vida e da morte se transferem, por deslizamento de sentido, para a percepção da ciência e do saber. A identificação com a figura de Oswaldo Cruz confere a estas duas entidades lugar privilegiado e sacralizado simbolicamente, no mesmo pedestal. Doença e cura formam a fronteira entre os que

\footnotetext{
5 Referência ao documento 'Monumento a Oswaldo Cruz' (parecer da comissão julgadora, emitido em 4.4.1940), parte da Coleção Monumento a Oswaldo Cruz, Caixa 1, maço 3.
} 
detêm o saber e os que vivem na ignorância. Enquanto esta identifica a morte, o saber se torna emblema da vida. O monumento não sugere qualquer relação entre saúde e as condições de vida, mas atribui importante função social à medicina e aos médicos. Estes são como que portadores do saber e da ciência, guardiães do progresso e da razão e detentores do poder de conjurar a morte. É o poder social da corporação dos médicos que se elabora e legitima.

A uma investigação aprofundada cabe apontar as relações que o projeto de erguimento de uma imagem urbana de sentido monumental dedicada a Oswaldo Cruz tem com o campo da medicina no Brasil. Se o poder simbólico é uma forma transfigurada de outras formas de poder, como quer Pierre Bourdieu (1989), devese rastrear a inserção desse projeto no tecido social, indicando como as lutas de representação se identificam com as lutas e projetos sociais correspondentes (Chartier, 1988). Nas fontes não se verifica qualquer disputa ou rivalidade entre projetos de imagens escultóricas diferenciadas. O que ressalta é o fato de a iniciativa do monumento se identificar com a promoção da campanha de combate ao câncer, ambas malogradas. A imagem de Oswaldo Cruz foi disputada por projetos distintos, que se valeram de recursos variados, mas, ao final, era sempre o mesmo personagem histórico que servia de emblema para discutir as bases da relação entre saúde e sociedade e entre sociedade e saber no Brasil.

\section{Paulo Knauss}

Departamento de História Universidade Federal Fluminense Campus do Gragoatá, Bloco O, sala 201 Niterói - RJ Brasil E-mail: pknauss@ibm.net

\section{Referências bibliográficas}

Agulhon, Maurice 1979

Agulhon, Maurice 1988

Bourdieu, Pierre 1989

Britto, Nara 1995

Chartier, Roger 1988

La Tardé,

Antônia Maria Amarante 1946

Nora, Pierre 1984
Marianne au combat, l'imagerie et la symbolique républicaines de 1789 a 1880. Paris, Flammarion.

Histoire vagabonde, etnologie et politique dans la France contemporaine. Paris, Gallimard.

O poder simbólico. Lisboa, Difel, cap. 1.

Oswaldo Cruz: a construção de um mito na ciência brasileira. Rio de Janeiro, Editora Fiocruz.

História cultural: entre práticas e representações. Lisboa, Difel.

Monumentos do Distrito Federal, Rio de Janeiro, s . ed.

'Entre mémoire et histoire'. Em Les lieux de mémoire. Paris, Gallimard, vol. I. 